Published in final edited form as:

Am J Prev Med. 2017 January ; 52(1): 10-19. doi:10.1016/j.amepre.2016.07.020.

\title{
Fish Consumption, Omega-3 Fatty Acids, and Risk of Cardiovascular Disease
}

\author{
Jinnie J. Rhee, MSc, ScD ${ }^{1,2,3,4,5}$, Eunjung Kim, $\mathbf{M S c}^{3}$, Julie E. Buring, ScD ${ }^{1,3}$, and Tobias \\ Kurth, MD, ScD ${ }^{1,3,6}$ \\ ${ }^{1}$ Department of Epidemiology, Harvard T.H. Chan School of Public Health, Boston, \\ Massachusetts \\ ${ }^{2}$ Department of Nutrition, Harvard T.H. Chan School of Public Health, Boston, Massachusetts \\ 3Division of Preventive Medicine, Department of Medicine, Brigham and Women's Hospital, \\ Boston, Massachusetts \\ 4Division of Aging, Department of Medicine, Brigham and Women's Hospital, Boston, \\ Massachusetts \\ ${ }^{5}$ Division of Nephrology, Department of Medicine, Stanford University School of Medicine, Palo \\ Alto, California \\ ${ }^{6}$ Institute of Public Health, Charité - Universitätsmedizin Berlin, Germany
}

\begin{abstract}
Introduction-Data on omega-3 polyunsaturated fatty acids in relation to cardiovascular disease are limited in women. The aim of this study was to examine longitudinal relations of tuna and dark fish, alpha-linolenic acid, and marine omega-3 fatty acid intake with incident major cardiovascular disease in women.
\end{abstract}

Methods-This was a prospective cohort study of U.S. women participating in the Women's Health Study from 1993 to 2014, during which the data were collected and analyzed. A total of 39,876 women who were aged $\geq 45$ years and free of cardiovascular disease at baseline provided dietary data on food frequency questionnaires. Analyses used Cox proportional hazards models to evaluate the association between fish and energy-adjusted omega-3 polyunsaturated fatty acid intake and the risk of major cardiovascular disease, defined as a composite outcome of myocardial infarction, stroke, and cardiovascular death, in 38,392 women in the final analytic sample (96\%).

Address correspondence to: Jinnie J. Rhee, MSc, ScD, Stanford University School of Medicine, Department of Medicine, Division of Nephrology, 1070 Arastradero Road \#3C3109, Palo Alto CA 94304. rheej@stanford.edu.

All authors have read the final version of the manuscript and approved its submission. The authors' contributions were as followsJJR and TK designed the research; EK performed the statistical analysis; JJR, JEB, and TK contributed to the interpretation of the data and made critical revisions to the manuscript for intellectual content; and JJR drafted the manuscript and had full access to all aspects of the research and writing process as well as primary responsibility for the final content.

No financial disclosures were reported by the authors of this paper.

Publisher's Disclaimer: This is a PDF file of an unedited manuscript that has been accepted for publication. As a service to our customers we are providing this early version of the manuscript. The manuscript will undergo copyediting, typesetting, and review of the resulting proof before it is published in its final citable form. Please note that during the production process errors may be discovered which could affect the content, and all legal disclaimers that apply to the journal pertain. 
Results-During 713,559 person years of follow-up, 1,941 cases of incident major cardiovascular disease were confirmed. Tuna and dark fish intake was not associated with the risk of incident major cardiovascular disease ( $p$-trend $>0.05$ ). Neither alpha-linolenic acid nor marine omega-3 fatty acid intake was associated with major cardiovascular disease or with individual cardiovascular outcomes (all $p$-trend $>0.05$ ). There was no effect modification by age, BMI, or baseline history of hypertension.

Conclusions-In this cohort of women without prior history of cardiovascular disease, intakes of tuna and dark fish, alpha-linolenic acid, and marine omega-3 fatty acids were not associated with risk of major cardiovascular disease.

\section{Introduction}

Cardiovascular disease (CVD) is one of the leading causes of death and premature disability in the U.S. ${ }^{1}$ Over the last few decades, the nutritional benefits of fish and polyunsaturated fatty acids on cardiovascular health have garnered great public health attention. Long-chain omega-3 polyunsaturated fatty acids (PUFAs) may prevent CVD by rendering antiarrhythmic effects and reduced blood viscosity, ${ }^{2,3}$ inhibiting platelet aggregation, ${ }^{4}$ lowering blood viscosity, ${ }^{3}$ suppressing inflammation, ${ }^{4}$ improving blood vessel function, ${ }^{5}$ and reducing plasma fibrinogen ${ }^{6}$ and insulin resistance. ${ }^{7}$ Previous studies have suggested that increased fish intake may lead to decreased risk of CVD in populations characterized by high levels of fish consumption such as those of Alaskan Natives, Greenland Eskimos, and the Japanese. ${ }^{8-11}$ However, findings from more recent cohort studies have been largely inconsistent. ${ }^{12-28}$ Many of these studies found no statistically significant inverse associations between fish intake and coronary heart disease (CHD) mortality, ${ }_{12,13,15,17,18,20}$ and some but not all cohort studies reported an inverse association between fish consumption and stroke risk. ${ }^{21-28}$ As most of the previous studies on fish and omega-3 PUFA intake and CVD have been conducted in non-U.S. populations or in populations that primarily consisted of men, data in U.S. women are limited. Therefore, this observational study prospectively examined the association between consumption of fish, specifically tuna and dark fish (mackerel, salmon, sardines, bluefish, and swordfish), long-chain omega-3 PUFA (alpha-linolenic acid [ALA] and marine omega-3 fatty acids) intake, and the incidence of major CVD among initially apparently healthy women enrolled in the Women's Health Study (WHS) during 22 years of follow-up.

\section{Methods}

\section{Study Design and Population}

The WHS was a randomized, placebo controlled trial of the effects of low-dose aspirin and vitamin $\mathrm{E}$ in the primary prevention of CVD and cancer. The design, methods, and main findings from the trial have been published previously. ${ }^{29,30}$ Briefly, at baseline, the study randomized 39,876 U.S. female health professionals aged $\geq 45$ years without a history of CVD, cancer, or other major illnesses to receive either active aspirin and placebo vitamin $\mathrm{E}$, active vitamin $\mathrm{E}$ and placebo aspirin, both active agents, or both placebos in a $2 \mathrm{X} 2$ factorial design. After the end of the trial in March 2004, women continued to be followed on an observational basis. Twice during the first year and yearly thereafter, women were sent 
questionnaires asking about demographic, lifestyle, and health information, including the occurrence of stroke events.

Study subjects included in this analysis were all participants in the WHS, and follow-up information from the time of randomization through December 31, 2014 was collected and analyzed. Of the 39,876 participating women, 15 participants with a history of CVD events (myocardial infarction [MI], stroke, coronary artery bypass grafting, and percutaneous transluminal coronary angioplasty) prior to randomization and 1,469 with missing data on dietary variables of interest were excluded, leaving 38,392 women (96\%) available for the analytic sample (Appendix Figure 1). This study was approved by the IRB of Brigham and Women's Hospital.

\section{Exposure}

Participants of the WHS completed a 131-item validated semiquantitative food frequency questionnaire (SFFQ) at baseline, ${ }^{31}$ from which total intakes of tuna (canned 3-4 ounces), dark fish (mackerel, salmon, sardines, bluefish, swordfish), and energy-adjusted ALA and marine omega-3 (eicosapentaenoic acid + docosahexaenoic acid, no alpha 18:3) fatty acids were assessed. The SFFQ has been tested and validated as a measure of long-term average dietary intakes in similar populations, and details on reliability and validity of estimates of fish and omega-3 fatty acid intakes have been published previously. ${ }^{32-35}$ This analytic approach of using self-reported SFFQ data follows recent recommendations for nutritional epidemiologic analyses. ${ }^{36}$

To show how frequently each food was consumed on average during the previous year, the SFFQ data were reported on a 9-point scale: 1 , never or less than once per month; 2 , one to three times per month; 3 , one time per week; 4 , two to four times per week; 5 , five to six times per week; 6 , once per day; 7 , two to three times per day; 8 , four to five times per day; and 9, six or more times per day. Given the small number of cases in the higher SFFQ frequency groups, the frequency groups were re-categorized to a 4-point scale. For tuna, Groups 4-9 were merged, and frequency values were added and redefined as more than one time per week. Likewise, Groups 3-7 were merged for dark fish, as there were no respondents in Groups 8-9, and then the frequency values were added and redefined as once or more per week. The frequency data for tuna and dark fish were added by taking the midpoint of each original frequency category value of the two variables separately, and converting it to a continuous measure of servings per day. The numbers obtained for tuna and dark fish were then added. The "never, or less than once per month" category was taken as the reference group. For ALA and marine omega-3 fatty acids, the frequency categories were divided into quintiles and the first quintile was taken as the reference category.

Nutrient values in foods were computed by multiplying the frequency of responses by the nutrient content of specified portion sizes based on the U.S. Department of Agriculture food composition data. ${ }^{37}$

\section{Outcome Measures}

The primary outcome of this analysis was a composite endpoint of nonfatal MI, nonfatal stroke, and cardiovascular death. During follow-up, participants provided self-reported data 
on incident physician diagnoses of cardiovascular events. Medical records were obtained for all cardiovascular events and reviewed by an Endpoints Committee of Physicians. The occurrence of MI was confirmed if symptoms met the WHO criteria of symptoms plus either typical electrocardiographic changes or abnormal levels of cardiac enzymes. ${ }^{38}$ Nonfatal stroke was confirmed if the participant had a new focal neurologic deficit of sudden or rapid onset that persisted for $>24$ hours, and then classified into major subtypes (ischemic, hemorrhagic, or unknown) based on available clinical and diagnostic information with good inter-rater agreement. ${ }^{39}$ Cardiovascular deaths were confirmed by review of autopsy reports, death certificates, medical records, or information obtained from next of kin or family members. The composite endpoint of medical record-confirmed MI, stroke, and cardiovascular death was defined as a major CVD event.

\section{Statistical Analysis}

Beginning at baseline, each participant was followed until the day of diagnosis of a major CVD event or censoring due to death from causes other than CVD or end of study, whichever came first. Cox proportional hazards models were used to calculate age-adjusted and multivariable-adjusted hazard ratios (HRs) and their 95\% CIs when analyzing the association between fish and energy-adjusted omega-3 PUFA intake and the risk of major CVD. The multivariable-adjusted model controlled for randomized treatment assignment, age, BMI, smoking, alcohol intake, physical activity, oral contraceptive use, hormone replacement therapy, multivitamin use, total energy intake, family history of MI, and baseline history of hypertension, high cholesterol, and diabetes. In a separate model, intakes of dietary fiber, fruits and vegetables, trans fat, sodium, and ratio of polyunsaturated to saturated fat were additionally adjusted for as covariates.

The proportionality assumptions of the Cox proportional hazards models were tested by including a logarithm of time-exposure interaction term and found no significant violation. To test for a linear trend, the median value of the energy-adjusted ALA and marine omega-3 PUFA intake was assigned to each quintile and modeled this variable as a continuous variable. To test for a linear trend for tuna and dark fish intake, a categorical variable was modeled as an ordinal variable.

Analyses were performed to test whether the association between energy-adjusted ALA and marine omega-3 PUFA intake and the risk of major CVD was modified by age $(<55,55-64$, or $\nsucceq 65$ years), BMI $(<25,25-30$, or $\geq 30)$, baseline history of hypertension (systolic blood pressure $\geq 140 \mathrm{mmHg}$, diastolic blood pressure $\geq 90 \mathrm{~mm} \mathrm{Hg}$, or self-reported physiciandiagnosed hypertension), or randomized treatment assignments.

All $p$-values were two-sided and analyses were performed at an alpha level of 0.05 using SAS, version 9.2.

\section{Results}

During 713,559 person years of follow-up, 1,941 incident major CVD cases were documented. Table 1 describes the distribution of baseline characteristics according to frequency of tuna and dark fish intake. Compared with women who rarely consumed tuna 
and dark fish, those who consumed more tuna and dark fish had higher BMI, higher levels of alcohol intake, were more physically active, and more likely to have baseline history of hypertension and high cholesterol. Women in the highest category of tuna and dark fish consumption were more likely to be current multivitamin users, and women who consumed more tuna and dark fish had higher intakes of dietary fiber, fruits and vegetables, sodium, and total calories but lower trans fat intake, compared with women who rarely consumed fish.

Table 2 shows the HRs of major CVD according to frequency of tuna and dark fish intake. Compared with women who consumed tuna and dark fish less than once per month, the multivariable-adjusted HRs for major CVD were 1.05 (95\% CI=0.92, 1.19) for those who had it one to three times per month, $1.01(95 \% \mathrm{CI}=0.88,1.16)$ for those who had it once per week, and $1.01(95 \% \mathrm{CI}=0.87,1.17)$ for those who had it more than one time per week ( $p$ trend=0.89). Adjusting for additional dietary variables such as intakes of dietary fiber, fruits and vegetables, trans fat, sodium, and ratio of polyunsaturated to saturated fat did not change the HRs.

No statistically significant associations between energy-adjusted ALA ( $p$-trend=0.64) or marine omega-3 fatty acids ( $p$-trend $=0.87$ ) and risk of major CVD were found across quintiles of intake in multivariable models (Table 3). Compared with women in the first quintile of ALA intake, those in the second, third, fourth, and fifth quintiles had multivariable-adjusted HRs of 0.92 (95\% CI=0.80, 1.06), 0.88 (95\% CI=0.76, 1.02), 0.95 $(95 \% \mathrm{CI}=0.82,1.09)$, and $0.99(95 \% \mathrm{CI}=0.87,1.14)$, respectively. With regard to marine omega-3 fatty acid intake, compared with women in the first quintile, those in the second, third, fourth, and fifth quintiles had multivariable-adjusted HRs of 0.94 (95\% CI=0.82, 1.08), 0.95 (95\% CI=0.82, 1.09), 0.96 (95\% $\mathrm{CI}=0.84,1.11)$, and 0.99 (95\% $\mathrm{CI}=0.86,1.13)$, respectively. Adjusting for intakes of dietary fiber, fruits and vegetables, trans fat, sodium, and ratio of polyunsaturated to saturated fat did not alter the results.

Upon examining the associations between intakes of ALA and marine omega- 3 fatty acids and the risk of individual cardiovascular endpoints, including MI, ischemic stroke, total stroke, and cardiovascular death (Table 4), there were no significant associations between either ALA or marine omega-3 fatty acids and the risk of any of the four individual cardiovascular endpoints (all $p$-trend $>0.05$ ). Adjusting for intakes of dietary fiber, fruits and vegetables, trans fat, sodium, and ratio of polyunsaturated to saturated fat did not lead to any substantial changes in the main findings.

Age and history of hypertension did not significantly modify the relationship between any of the main exposures of interest and the risk of major CVD (all $p$-values for interaction $>0.05$ ). The interaction $p$-value for BMI and marine omega-3 fatty acid intake was only marginally significant ( $p=0.04$ ), and the associations across different strata of BMI were not statistically significant. There was no effect modification by BMI on the association between intakes of tuna and dark fish and ALA, and major CVD (all $p$-values for interaction >0.05). There was no statistically significant interaction of the association of primary exposure of interest (tuna and dark fish intake) with outcomes by randomized treatment assignments (for interaction, $p=0.65)$. 


\section{Discussion}

In this large prospective cohort of initially apparently healthy women, intakes of tuna and dark fish, ALA, and marine omega-3 PUFAs were not associated with the risk of major CVD. Long-chain omega-3 PUFAs were also not associated with individual CVD events such as MI, ischemic and total stroke, and CVD death. In stratified analyses, there was no evidence of effect modification by age, BMI, baseline history of hypertension, or randomized treatment assignments for any of the exposures.

Many, but not all, previous cohort studies and RCTs of diet and fish oil supplements have reported an inverse association between fish or omega-3 PUFAs and CVD. ${ }^{40-42}$ In the midst of limited prospective data on fish and omega-3 PUFAs and risk of CHD in women, a study conducted among women in the Nurses' Health Study reported an inverse association between fish intake and CHD death. ${ }^{43}$ In the EURAMIC (EURopean multicentre casecontrol study on Antioxidants, Myocardial Infarction and Cancer of the breast) Study, Guallar et al. ${ }^{44}$ found that adipose tissue ALA was associated with a lower risk of MI, but this association became nonsignificant after adjusting for other risk factors. By contrast, $\mathrm{Hu}$ and colleagues ${ }^{45}$ reported a dose-response relationship between dietary ALA intake and risk of fatal ischemic heart disease, with a $45 \%$ reduction in risk in the highest quintile of intake. The null findings of this study are in accordance with other previous prospective studies. ${ }^{13,17,18,46,47}$ For example, in a sample of postmenopausal women in the Iowa Women's Health Study, there was no association between fish intake and CHD or stroke mortality. ${ }^{13}$ Similarly, a study done in middle-aged men in the Zutphen Study did not find an association between fatty fish consumption or eicosapentaenoic acid + docosahexaenoic acid intake and CHD death, ${ }^{17}$ and there was no evidence in support of the relation of fish consumption with cerebral hemorrhage death, cerebral infarction death, or CHD death in a population of Japanese men and women. ${ }^{18}$

Studies on omega-3 PUFAs and stroke have also yielded mixed results. In a recent metaanalysis of prospective studies of fish intake and stroke risk, Larsson et al. ${ }^{48}$ reported a weak inverse association with a relative risk of $0.94(95 \% \mathrm{CI}=0.89,0.99)$ for an increase in consumption of three servings per day. The null findings of this study are consistent with results of a meta-analysis of eight prospective studies on long-chain omega-3 PUFAs and stroke, which showed no evidence for the association between omega-3 PUFA intake and the risk of stroke. ${ }^{49}$

Taken together, the inconsistencies in the literature on fish and omega-3 PUFA intake and CVD suggest that there could be substantial heterogeneity in the way fish, omega-3 PUFAs, and fish oil can have an effect on CVD risk. The cardioprotective effects of fish and longchain omega-3 PUFAs may be influenced by other clinical conditions and comorbidities, and depend on whether the study is done in a primary or secondary prevention setting. Possible mechanisms for the known protective effects of fish and long-chain omega-3 PUFA may be lowered blood viscosity, ${ }^{3}$ inhibition of platelet aggregation and decreased platelet retention, ${ }^{3}$ generation of anti-inflammatory effects through the inhibition of leukotrienemediated functions of neutrophils, ${ }^{50}$ and possible modulation of membrane ion channel functions due to a change in the fatty acid distribution in plasma membrane phospholipids. ${ }^{51}$ 
Improved endothelial function and increased arterial compliance can work as a secondary mechanism to generate a mild hypotensive effect. ${ }^{41,52,53}$ Fatty acids can further play a role in reducing the risk of CVD by eliciting antithrombogenic and hypotriglyceridemic effects. ${ }^{54}$ Though the protective effects of fish and long-chain omega-3 PUFAs on CVD risk may have plausible biological basis, inconsistent epidemiologic data suggest that further investigation of the potential beneficial effects of fish and fatty acids on cardiovascular health is warranted in different study populations, especially those consisting of healthy women. On the other hand, high omega-3 indices have been associated with increased risk of CHD, which may influence detection of a positive effect for lower indices. ${ }^{55}$ Future studies should also examine how and to what extent these biological effects of omega-3 fatty acids are influenced by various clinical factors, and what impact this would have on implementation of therapeutic interventions.

\section{Limitations}

Several limitations should be considered when interpreting these findings. Random misclassification of exposure resulting from self-reported information on dietary intake is possible, as this study is observational. However, health professionals are known to report their health status more accurately than the general population and the dietary assessment used in this study is identical to that used in many previously published population-based studies, which have been validated in similar populations. It is possible that this study did not capture complete information regarding fish and omega-3 PUFA consumption over time. In this study, only a single assessment of dietary exposure at baseline was used. This could fail to capture cumulative intake or changes in intake during long-term follow-up, making it subject to random error of self-report and underestimation of true associations. The generalizability of study findings may be limited because this study only consisted of relatively healthy women who were mostly white health professionals. Nevertheless, it is not expected that mechanisms of these agents that would affect health professional differently than other cohorts of women. Lastly, because this study was observational, residual confounding may be present despite the adjustments made for potential confounding factors.

The strengths of this study include a large overall sample size, prospective study design, long follow-up period, high participation rate, detailed and standardized diet assessment, confirmation of cases of cardiovascular events after a thorough medical record review, and consideration of a wide range of potential confounders.

\section{Conclusions}

In this large prospective cohort study of women, tuna and dark fish intake and long-chain omega-3 PUFAs were not associated with risk of major CVD or individual CVD events, such as MI, ischemic and total stroke, and CVD death. As this study population was limited to those without prior CVD events, these data may suggest that low-risk groups may not necessarily benefit from fish and omega- 3 fatty acid supplementation or intervention. Although some previous studies have suggested benefit of adding fish and omega-3 PUFAs as part of a healthy diet, the independent health benefits of fish consumption and intakes of ALA and marine omega-3 fatty acids could not be verified in this cohort of women. 


\section{Supplementary Material}

Refer to Web version on PubMed Central for supplementary material.

\section{Acknowledgments}

The research presented in this paper is that of the authors and does not reflect the official policy of NIH. This work was supported by NIH grants 5T32AG000158-23 and 5T32DK007357-29. The Women's Health Study is supported by grants from NIH (HL-043851, HL-080467, HL-099355, CA-047988, and UM1 CA182913). The funding sources had no role in the design and conduct of the study; collection, management, analysis, and interpretation of the data; preparation, review, or approval of the manuscript, or the decision to submit the manuscript for publication.

\section{References}

1. Bauer UE, Briss PA, Goodman RA, et al. Prevention of chronic disease in the 21st century: elimination of the leading preventable causes of premature death and disability in the USA. Lancet. 2014; 384(9937):45-52. http://dx.doi.org/10.1016/S0140-6736(14)60648-6. [PubMed: 24996589]

2. Dyerberg J, Bang HO, Stoffersen E, et al. Eicosapentaenoic acid and prevention of thrombosis and atherosclerosis? Lancet. 1978; 2(8081):117-119. http://dx.doi.org/10.1016/ S0140-6736(78)91505-2. [PubMed: 78322]

3. Terano T, Hirai A, Hamazaki T, et al. Effect of oral administration of highly purified eicosapentaenoic acid on platelet function, blood viscosity and red cell deformability in healthy human subjects. Atherosclerosis. 1983; 46(3):321-331. http://dx.doi.org/ 10.1016/0021-9150(83)90181-8. [PubMed: 6303363]

4. Leaf A, Weber PC. Cardiovascular effects of n-3 fatty acids. N Engl J Med. 1988; 318(9):549-557. http://dx.doi.org/10.1056/NEJM198803033180905. [PubMed: 3277056]

5. De Caterina R, Liao JK, Libby P. Fatty acid modulation of endothelial activation. Am J Clin Nutr. 2000; 71(1 Suppl):213s-223s. [PubMed: 10617974]

6. Hostmark AT, Bjerkedal T, Kierulf P, et al. Fish oil and plasma fibrinogen. BMJ. 1988; 297(6642): 180-181. http://dx.doi.org/10.1136/bmj.297.6642.180. [PubMed: 3044509]

7. Storlien LH, Kraegen EW, Chisholm DJ, et al. Fish oil prevents insulin resistance induced by highfat feeding in rats. Science. 1987; 237(4817):885-888. http://dx.doi.org/10.1126/science.3303333. [PubMed: 3303333]

8. Newman WP, Middaugh JP, Propst MT, et al. Atherosclerosis in Alaska Natives and non-natives. Lancet. 1993; 341(8852):1056-1057. http://dx.doi.org/10.1016/0140-6736(93)92413-N. [PubMed: 8096960]

9. Middaugh JP. Cardiovascular deaths among Alaskan Natives, 1980-86. Am J Public Health. 1990; 80(3):282-285. http://dx.doi.org/10.2105/AJPH.80.3.282. [PubMed: 2305905]

10. Kromann N, Green A. Epidemiological studies in the Upernavik district, Greenland Incidence of some chronic diseases 1950-1974. Acta Med Scand. 1980; 208(5):401-406. [PubMed: 7457208]

11. Hirai A, Hamazaki T, Terano T, et al. Eicosapentaenoic acid and platelet function in Japanese. Lancet. 1980; 2(8204):1132-1133. http://dx.doi.org/10.1016/S0140-6736(80)92558-1. [PubMed: 6107739]

12. Iso H, Kobayashi M, Ishihara J, et al. Intake of fish and $n 3$ fatty acids and risk of coronary heart disease among Japanese: the Japan Public Health Center-Based (JPHC) Study Cohort I. Circulation. 2006; 113(2):195-202. http://dx.doi.org/10.1161/CIRCULATIONAHA.105.581355. [PubMed: 16401768]

13. Folsom AR, Demissie Z. Fish intake, marine omega-3 fatty acids, and mortality in a cohort of postmenopausal women. Am J Epidemiol. 2004; 160(10):1005-1010. http://dx.doi.org/ 10.1093/aje/kwh307. [PubMed: 15522857]

14. Jarvinen R, Knekt P, Rissanen H, et al. Intake of fish and long-chain n-3 fatty acids and the risk of coronary heart mortality in men and women. Br J Nutr. 2006; 95(4):824-829. http://dx.doi.org/ 10.1079/BJN20051687. [PubMed: 16571163] 
15. Yamagishi K, Iso H, Date C, et al. Fish, omega-3 polyunsaturated fatty acids, and mortality from cardiovascular diseases in a nationwide community-based cohort of Japanese men and women the JACC (Japan Collaborative Cohort Study for Evaluation of Cancer Risk) Study. J Am Coll Cardiol. 2008; 52(12):988-996. http://dx.doi.org/10.1016/j.jacc.2008.06.018. [PubMed: 18786479]

16. de Goede J, Geleijnse JM, Boer JM, et al. Marine (n-3) fatty acids, fish consumption, and the 10year risk of fatal and nonfatal coronary heart disease in a large population of Dutch adults with low fish intake. J Nutr. 2010; 140(5):1023-1028. http://dx.doi.org/10.3945/jn.109.119271. [PubMed: 20335635]

17. Streppel MT, Ocke MC, Boshuizen HC, et al. Long-term fish consumption and n-3 fatty acid intake in relation to (sudden) coronary heart disease death: the Zutphen study. Eur Heart J. 2008; 29(16):2024-2030. http://dx.doi.org/10.1093/eurheartj/ehn294. [PubMed: 18641046]

18. Nakamura Y, Ueshima H, Okamura T, et al. Association between fish consumption and all-cause and cause-specific mortality in Japan: NIPPON DATA80, 1980-99. Am J Med. 2005; 118(3):239245. http://dx.doi.org/10.1016/j.amjmed.2004.12.016. [PubMed: 15745721]

19. Tomasallo C, Anderson H, Haughwout M, et al. Mortality among frequent consumers of Great Lakes sport fish. Environ Res. 2010; 110(1):62-69. http://dx.doi.org/10.1016/j.envres.2009.09.008. [PubMed: 19811780]

20. Manger MS, Strand E, Ebbing M, et al. Dietary intake of n-3 long-chain polyunsaturated fatty acids and coronary events in Norwegian patients with coronary artery disease. Am J Clin Nutr. 2010; 92(1):244-251. http://dx.doi.org/10.3945/ajen.2010.29175. [PubMed: 20484456]

21. Keli SO, Feskens EJ, Kromhout D. Fish consumption and risk of stroke, The Zutphen Study. Stroke. 1994; 25(2):328-332. http://dx.doi.org/10.1161/01.STR.25.2.328. [PubMed: 8303739]

22. Morris MC, Manson JE, Rosner B, et al. Fish consumption and cardiovascular disease in the physicians' health study: a prospective study. Am J Epidemiol. 1995; 142(2):166-175. [PubMed: 7598116]

23. Orencia AJ, Daviglus ML, Dyer AR, et al. Fish consumption and stroke in men, 30-year findings of the Chicago Western Electric Study. Stroke. 1996; 27(2):204-209. http://dx.doi.org/ 10.1161/01.STR.27.2.204. [PubMed: 8571410]

24. Gillum RF, Mussolino ME, Madans JH. The relationship between fish consumption and stroke incidence, The NHANES I Epidemiologic Follow-up Study (National Health and Nutrition Examination Survey). Arch Intern Med. 1996; 156(5):537-542. http://dx.doi.org/10.1001/archinte. 1996.00440050091010. [PubMed: 8604960]

25. Yuan JM, Ross RK, Gao YT, et al. Fish and shellfish consumption in relation to death from myocardial infarction among men in Shanghai, China. Am J Epidemiol. 2001; 154(9):809-816. http://dx.doi.org/10.1093/aje/154.9.809. [PubMed: 11682363]

26. Iso H, Rexrode KM, Stampfer MJ, et al. Intake of fish and omega-3 fatty acids and risk of stroke in women. JAMA. 2001; 285(3):304-312. http://dx.doi.org/10.1001/jama.285.3.304. [PubMed: 11176840]

27. He K, Rimm EB, Merchant A, et al. Fish consumption and risk of stroke in men. JAMA. 2002; 288(24):3130-3136. http://dx.doi.org/10.1001/jama.288.24.3130. [PubMed: 12495393]

28. Sauvaget C, Nagano J, Allen N, et al. Intake of animal products and stroke mortality in the Hiroshima/Nagasaki Life Span Study. Int J Epidemiol. 2003; 32(4):536-543. http://dx.doi.org/ 10.1093/ije/dyg151. [PubMed: 12913025]

29. Ridker PM, Cook NR, Lee IM, et al. A randomized trial of low-dose aspirin in the primary prevention of cardiovascular disease in women. N Engl J Med. 2005; 352(13):1293-1304. http:// dx.doi.org/10.1056/NEJMoa050613. [PubMed: 15753114]

30. Lee IM, Cook NR, Gaziano JM, et al. Vitamin E in the primary prevention of cardiovascular disease and cancer: the Women's Health Study: a randomized controlled trial. JAMA. 2005; 294(1):56-65. http://dx.doi.org/10.1001/jama.294.1.56. [PubMed: 15998891]

31. Willett, W. Nutritional Epidemiology. 3. New York: Oxford University Press; 2012. http:// dx.doi.org/10.1093/acprof:oso/9780199754038.001.0001

32. Willett WC, Sampson L, Stampfer MJ, et al. Reproducibility and validity of a semiquantitative food frequency questionnaire. Am J Epidemiol. 1985; 122(1):51-65. [PubMed: 4014201] 
33. Salvini S, Hunter DJ, Sampson L, et al. Food-based validation of a dietary questionnaire: the effects of week-to-week variation in food consumption. Int J Epidemiol. 1989; 18(4):858-867. http://dx.doi.org/10.1093/ije/18.4.858. [PubMed: 2621022]

34. Feskanich D, Rimm EB, Giovannucci EL, et al. Reproducibility and validity of food intake measurements from a semiquantitative food frequency questionnaire. J Am Diet Assoc. 1993; 93(7):790-796. http://dx.doi.org/10.1016/0002-8223(93)91754-E. [PubMed: 8320406]

35. Hunter DJ, Rimm EB, Sacks FM, et al. Comparison of measures of fatty acid intake by subcutaneous fat aspirate, food frequency questionnaire and diet records in a free-living population of US men. Am J Epidemiol. 1992; 135(4):418-427. [PubMed: 1550093]

36. Subar AF, Freedman LS, Tooze JA, et al. Addressing Current Criticism Regarding the Value of Self-Report Dietary Data. J Nutr. 2015; 145(12):2639-2645. http://dx.doi.org/10.3945/jn. 115.219634. [PubMed: 26468491]

37. Lin J, Manson JE, Lee I-M, et al. Intakes of calcium and vitamin D and breast cancer risk in women. Arch Intern Med. 2007; 167(10):1050-1059. http://dx.doi.org/10.1001/archinte. 167.10.1050. [PubMed: 17533208]

38. Liu S, Manson JE, Lee IM, et al. Fruit and vegetable intake and risk of cardiovascular disease: the Women's Health Study. Am J Clin Nutr. 2000; 72(4):922-928. [PubMed: 11010932]

39. Atiya M, Kurth T, Berger K, et al. Interobserver agreement in the classification of stroke in the Women's Health Study. Stroke. 2003; 34(2):565-567. http://dx.doi.org/10.1161/01.STR. 0000054159.21017.7C. [PubMed: 12574576]

40. Harper CR, Jacobson TA. The fats of life: the role of omega-3 fatty acids in the prevention of coronary heart disease. Arch Intern Med. 2001; 161(18):2185-2192. http://dx.doi.org/10.1001/ archinte.161.18.2185. [PubMed: 11575974]

41. Kris-Etherton PM, Harris WS, Appel LJ. American Heart Association Nutrition Committee. Fish consumption, fish oil, omega-3 fatty acids, and cardiovascular disease. Circulation. 2002; 106(21): 2747-2757. http://dx.doi.org/10.1161/01.CIR.0000038493.65177.94. [PubMed: 12438303]

42. Marckmann P, Gronbaek M. Fish consumption and coronary heart disease mortality, A systematic review of prospective cohort studies. Eur J Clin Nutr. 1999; 53(8):585-590. http://dx.doi.org/ 10.1038/sj.ejcn.1600832. [PubMed: 10477243]

43. Hu FB, Bronner L, Willett WC, et al. Fish and omega-3 fatty acid intake and risk of coronary heart disease in women. JAMA. 2002; 287(14):1815-1821. http://dx.doi.org/10.1001/jama.287.14.1815. [PubMed: 11939867]

44. Guallar E, Aro A, Jimenez FJ, et al. Omega-3 fatty acids in adipose tissue and risk of myocardial infarction: the EURAMIC study. Arterioscler Thromb Vasc Biol. 1999; 19(4):1111-1118. http:// dx.doi.org/10.1161/01.ATV.19.4.1111. [PubMed: 10195943]

45. Hu FB, Stampfer MJ, Manson JE, et al. Dietary intake of alpha-linolenic acid and risk of fatal ischemic heart disease among women. Am J Clin Nutr. 1999; 69(5):890-897. [PubMed: 10232627]

46. Ascherio A, Rimm EB, Stampfer MJ, et al. Dietary intake of marine n-3 fatty acids, fish intake, and the risk of coronary disease among men. N Engl J Med. 1995; 332(15):977-982. http:// dx.doi.org/10.1056/NEJM199504133321501. [PubMed: 7885425]

47. Osler M, Andreasen AH, Hoidrup S. No inverse association between fish consumption and risk of death from all-causes, and incidence of coronary heart disease in middle-aged, Danish adults. J Clin Epidemiol. 2003; 56(3):274-279. http://dx.doi.org/10.1016/S0895-4356(02)00600-5. [PubMed: 12725883]

48. Larsson SC, Orsini N. Fish consumption and the risk of stroke: a dose-response meta-analysis. Stroke. 2011; 42(12):3621-3623. http://dx.doi.org/10.1161/STROKEAHA.111.630319. [PubMed: 21903950]

49. Larsson SC, Orsini N, Wolk A. Long-chain omega-3 polyunsaturated fatty acids and risk of stroke: a meta-analysis. Eur J Epidemiol. 2012; 27(12):895-901. http://dx.doi.org/10.1007/ s10654-012-9748-9. [PubMed: 23179632]

50. Lee TH, Hoover RL, Williams JD, et al. Effect of dietary enrichment with eicosapentaenoic and docosahexaenoic acids on in vitro neutrophil and monocyte leukotriene generation and neutrophil 
function. N Engl J Med. 1985; 312(19):1217-1224. http://dx.doi.org/10.1056/ NEJM198505093121903. [PubMed: 2985986]

51. Dyerberg J, Eskesen DC, Andersen PW, et al. Effects of trans- and n-3 unsaturated fatty acids on cardiovascular risk markers in healthy males, An 8 weeks dietary intervention study. Eur J Clin Nutr. 2004; 58(7):1062-1070. http://dx.doi.org/10.1038/sj.ejcn.1601934. [PubMed: 15220949]

52. Chin JP, Dart AM. How do fish oils affect vascular function? Clin Exp Pharmacol Physiol. 1995; 22(2):71-81. http://dx.doi.org/10.1111/j.1440-1681.1995.tb01959.x. [PubMed: 7621612]

53. McVeigh GE, Brennan GM, Cohn JN, et al. Fish oil improves arterial compliance in non-insulindependent diabetes mellitus. Arterioscler Thromb. 1994; 14(9):1425-1429. http://dx.doi.org/ 10.1161/01.ATV.14.9.1425. [PubMed: 8068603]

54. Connor WE. Importance of n-3 fatty acids in health and disease. Am J Clin Nutr. 2000; 71(1 Suppl):171S-175S. [PubMed: 10617967]

55. Harris WS. The omega-3 index as a risk factor for coronary heart disease. Am J Clin Nutr. 2008; 87(6):1997S-2002S. [PubMed: 18541601] 


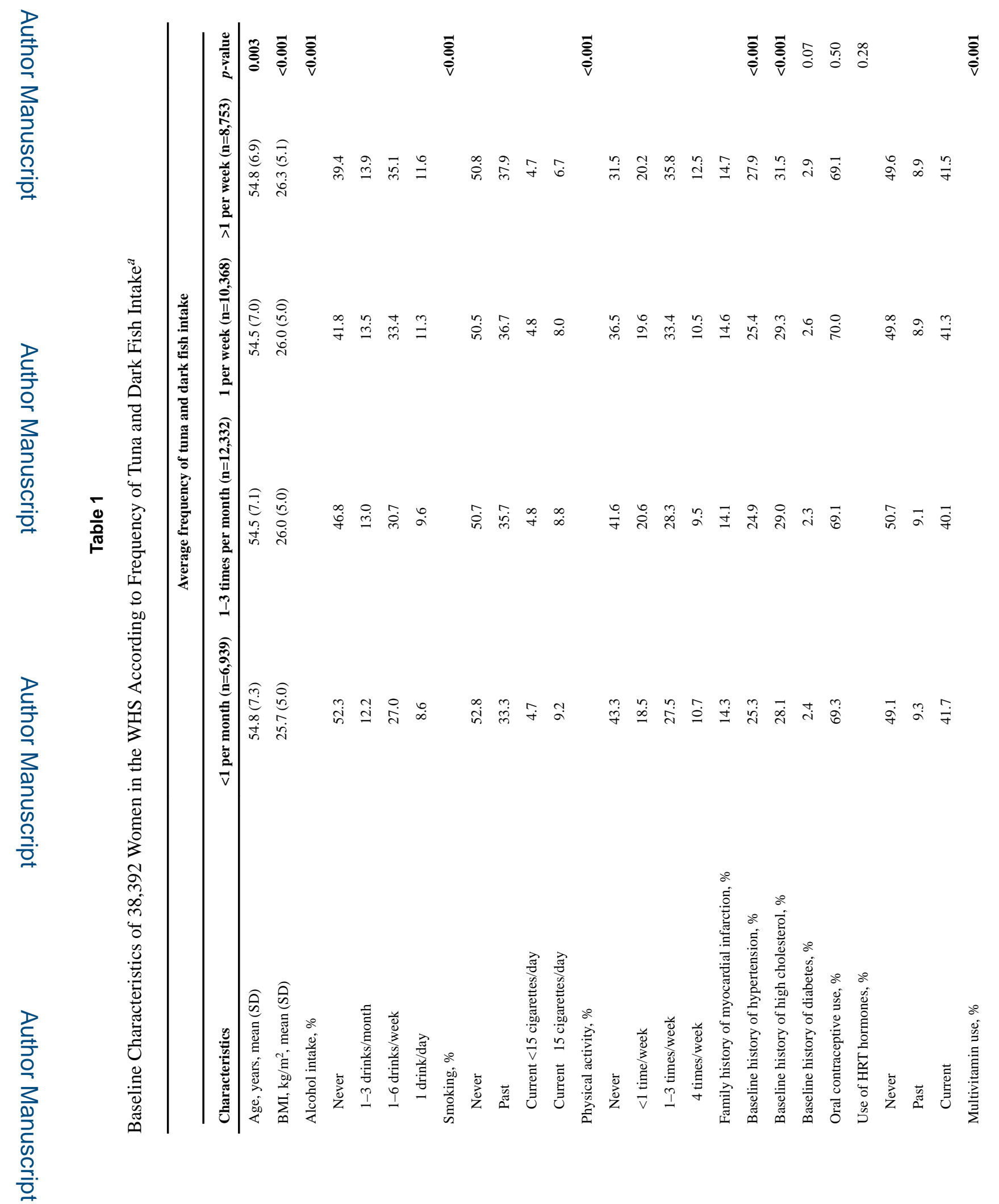

Am J Prev Med. Author manuscript; available in PMC 2018 January 01. 
Rhee et al.

Page 13

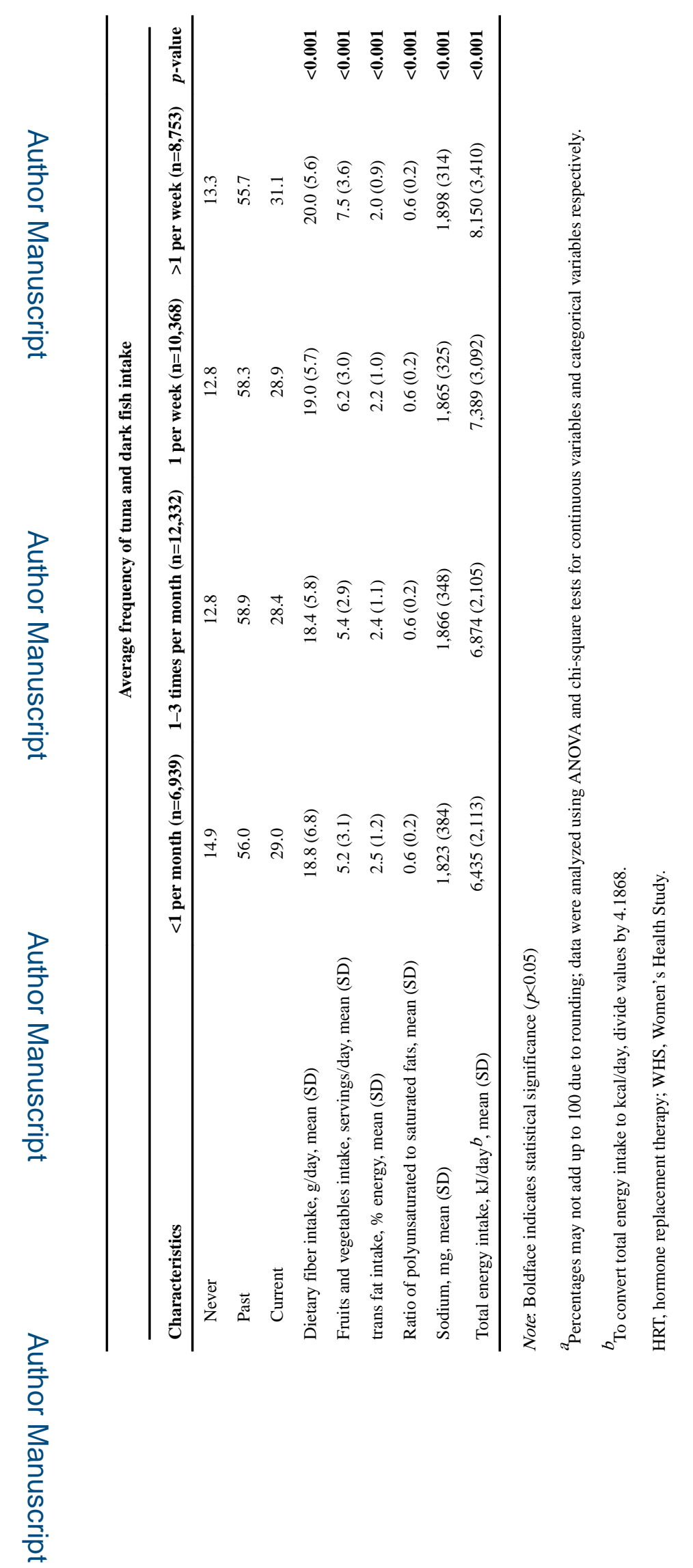

Am J Prev Med. Author manuscript; available in PMC 2018 January 01. 

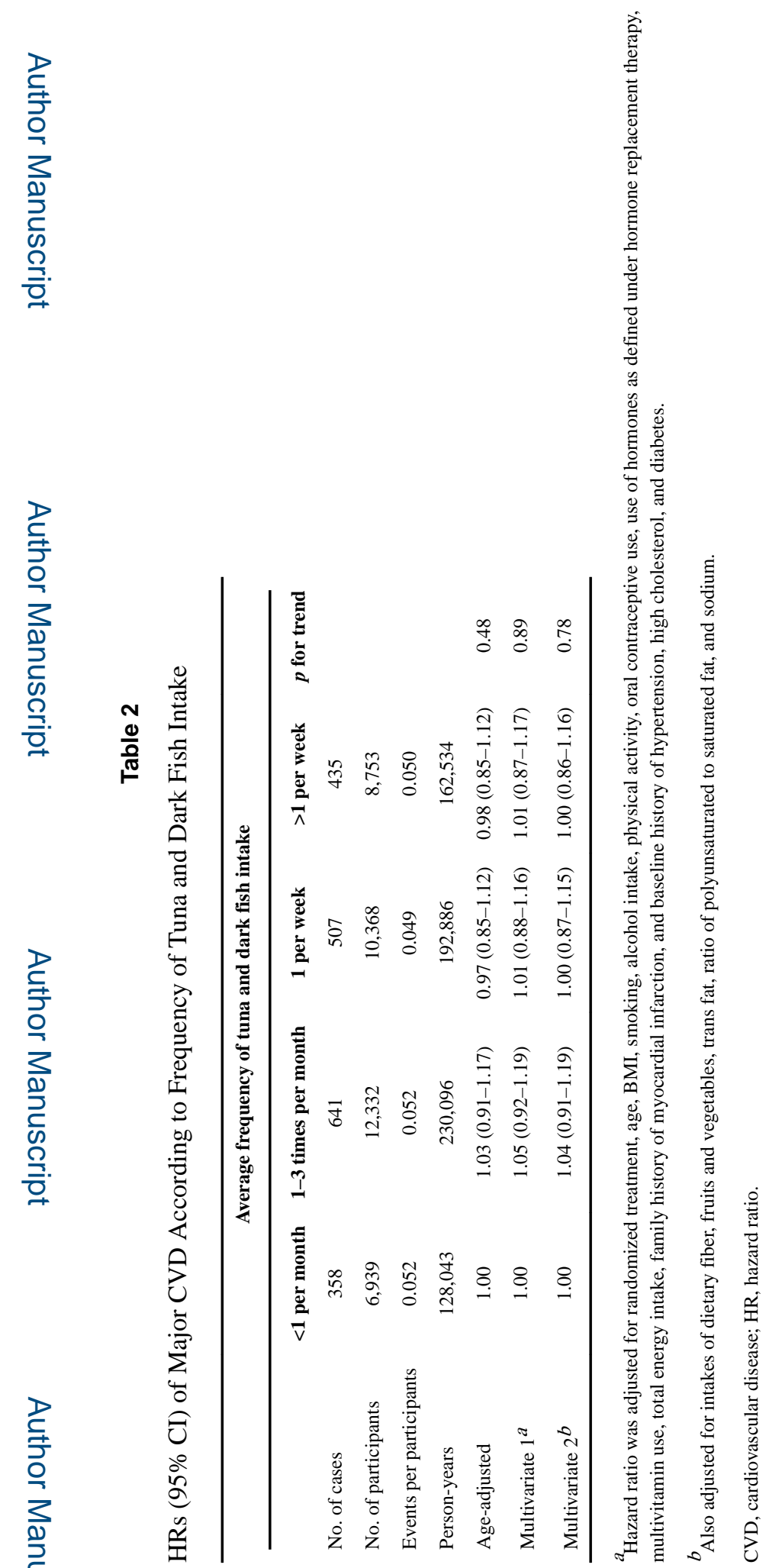

Am J Prev Med. Author manuscript; available in PMC 2018 January 01 


\section{록 \\ ํㅗㄹ}

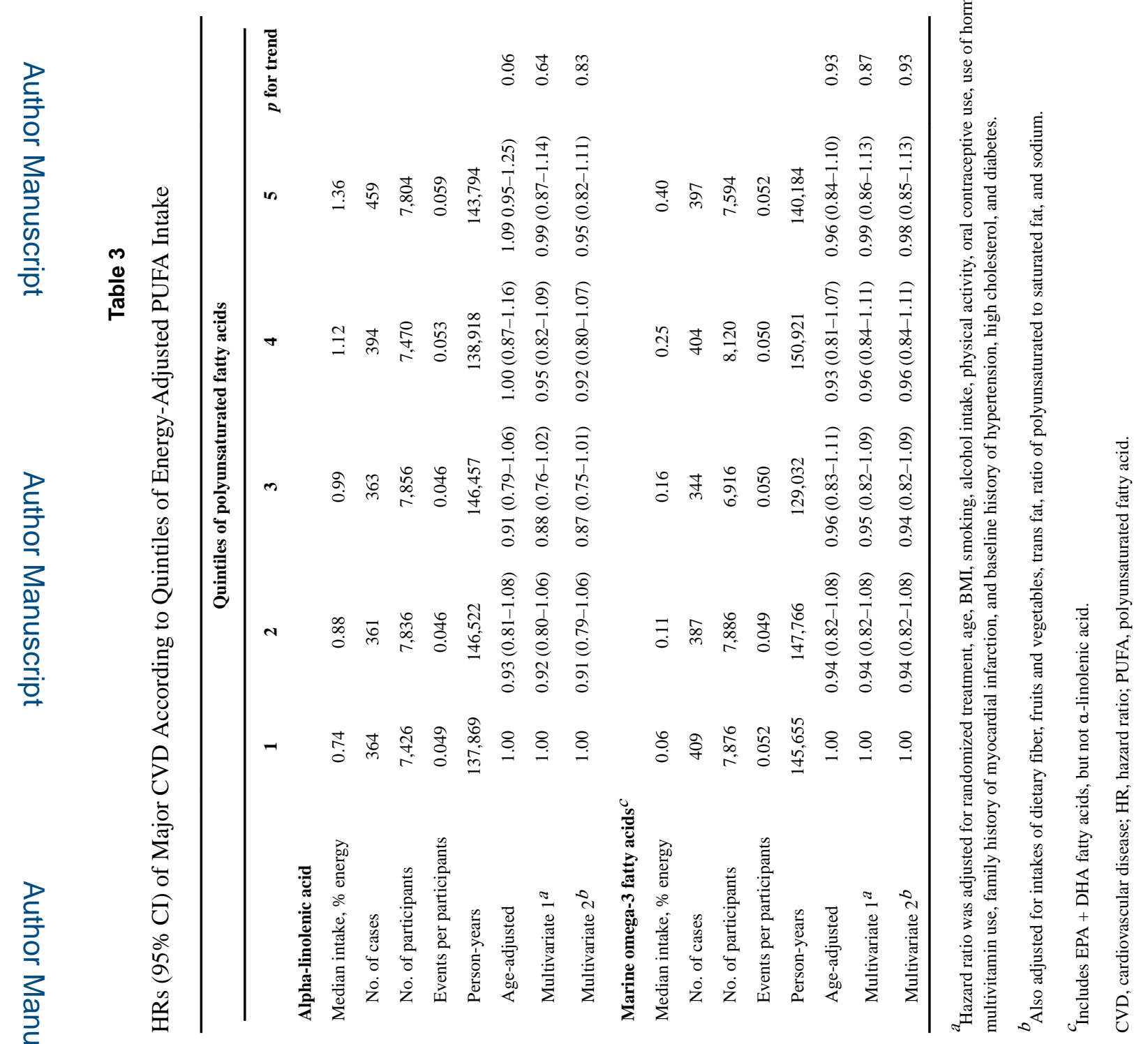

Am J Prev Med. Author manuscript; available in PMC 2018 January 01. 


\section{을 \\ 골}

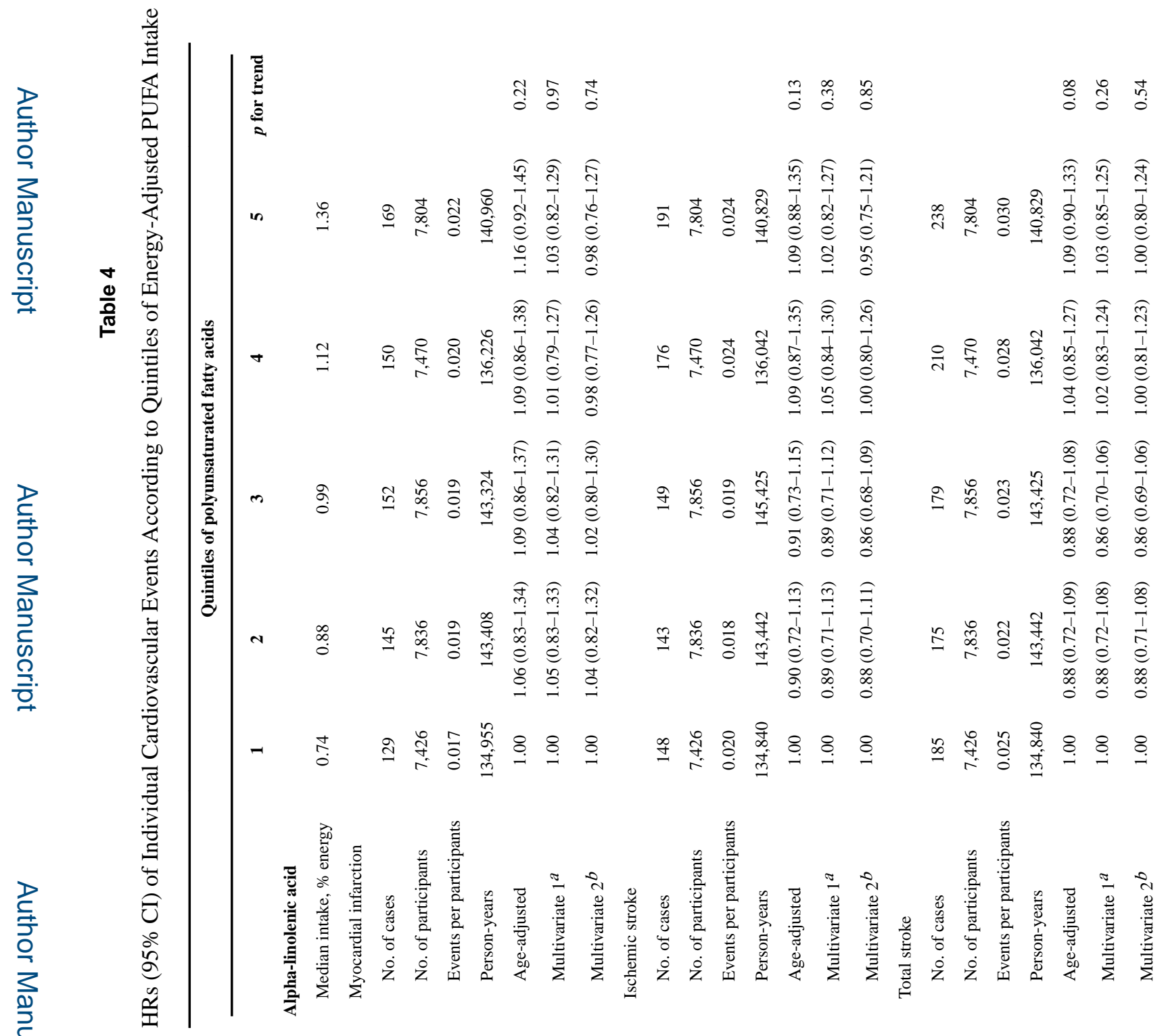

Am J Prev Med. Author manuscript; available in PMC 2018 January 01. 


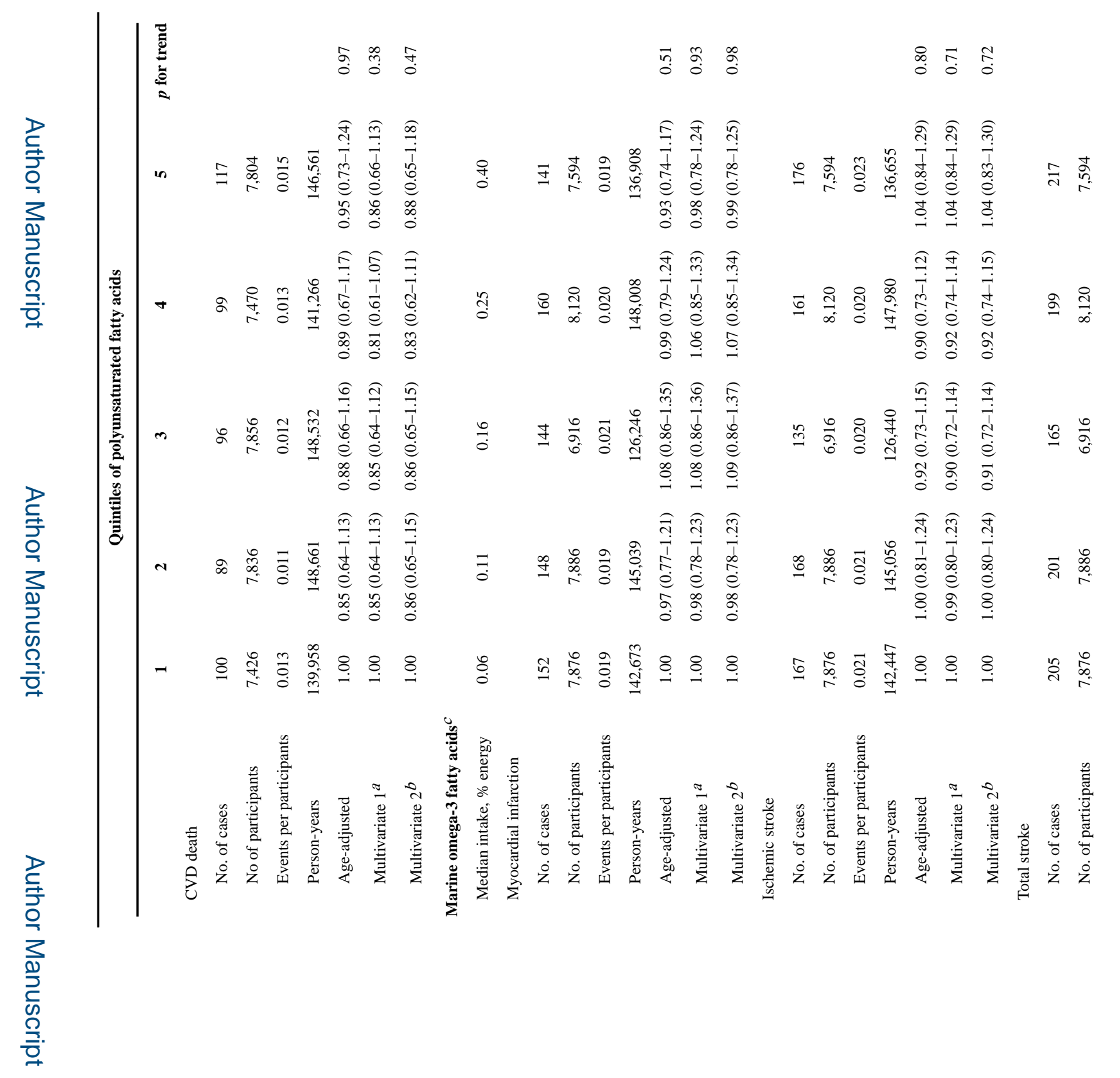

로을

Am J Prev Med. Author manuscript; available in PMC 2018 January 01. 


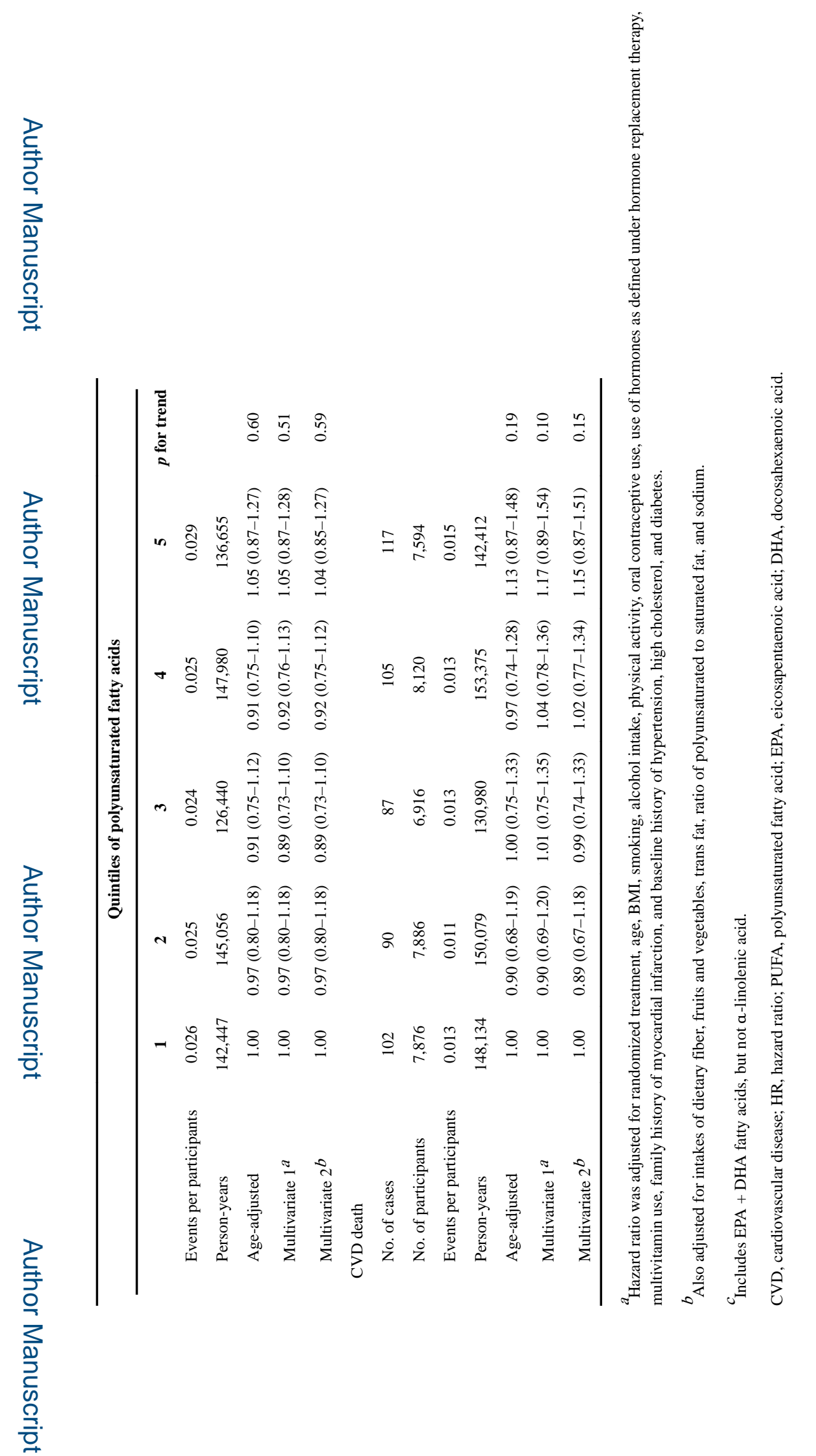

Am J Prev Med. Author manuscript; available in PMC 2018 January 01. 